\title{
Antibacterial, antifungal, anti-oxidant, anti-inflammatory and anti-hypertensive activities of $\mathrm{N}$-chloropyrazinamide
}

\author{
S. Parimala Vaijayanthi ${ }^{1, \star}, \mathbf{N}$. Mathiyalagan ${ }^{2}$ \\ ${ }^{1}$ Department of Chemistry, M.A.M. College of Engineering and Technology, Siruganur, \\ Tiruchirappalli - 621 105, Tamil Nadu, India \\ ${ }^{2}$ Department of Chemistry, Jayaram College of Engineering and Technology, \\ Karattampatti - Pagalavadi, Thuraiyur (Tk), Tiruchirappalli - 621 014, Tamil Nadu, India \\ *E-mail address: spv.sjc@gmail.com
}

\begin{abstract}
N-chloropyrazinamide was prepared by the chlorination of pyrazinamide using trichloroisocyanuric acid. The experimental results ascertained that the tested N-chloropyrazinamide showed good antimicrobial activities when compared to standard drug. It was found that $\mathrm{N}$ chloropyrazinamide at different concentrations exhibited significant dose dependent anti-oxidant, anti-inflammatory and anti-hypertensive activity.
\end{abstract}

Keywords: antibacterial activity; antifungal activity; anti-oxidant activity; anti-inflammatory; antihypertensive activity; N-chloropyrazinamide

\section{INTRODUCTION}

Great attention has been paid for curing diseases caused by microorganisms. Many infectious pathogenic microorganisms develop resistance against the prevailing drugs, and this situation has necessitated a search for new source of compounds. Functionalized nitrogen and oxygen containing heterocycles play a predominant role in medicinal chemistry and they have been intensively used as scaffolds for drug development. The rapid assemble of molecular diversity is an important goal of synthetic organic chemistry and is one of the key paradigms of modern drug discovery.

Pyrazinamide is one of the most effective anti-tuberculous drugs. Pyrazine and pyrazinamide analogs exhibited potent antibacterial activity, e.g. pyrazinoic acid esters ${ }^{1}$, pyrazine thiocarboxamide ${ }^{2}$ and ring substituted pyrazinylchalcones ${ }^{3}$. Pyrazine carboxamide derivatives have been reported to possess diverse pharmacological activities including antimicrobial activity, fungicidal activity, herbicidal activity, anti-oxidant activity and antialgal activity ${ }^{4-11}$. Although the pyrazine ring system has proved to be an interesting class in heterocyclic chemistry; it has received little attention in the literature. Some of its derivatives are important as anticancer agents with low toxicity ${ }^{12}$, anti-inflammatory ${ }^{13}$, blood platelet aggregation inhibitors, bone metabolism improvers, adenosine antagonists and controlling herbicides ${ }^{14}$. They also show antifungal and antiparasitic activities ${ }^{15}$. In addition, they are used as disperse dyes and as fluorescents. 


\section{MATERIALS AND METHODS}

All the reagents and solvents used were purchased from Merck, India and used without further purification.

\section{EXPERIMENTAL}

\section{1. Preparation of $\mathrm{N}$-chloropyrazinamide}

A simple procedure was developed for the preparation of $\mathrm{N}$-chloropyrazinamide (NCPZA). In a $100 \mathrm{~mL}$ round-bottom flask, $0.6894 \mathrm{~g}(5.605 \mathrm{mmol})$ of pyrazinamide (PZA) was dissolved in methyl acetate. Trichloroisocyanuric acid, $0.478 \mathrm{~g}(2.057 \mathrm{mmol})$ was added and a precipitate of cyanuric acid formed after $20 \mathrm{~min}$. After stirring for $4 \mathrm{~h}$, the mixture was vacuum filtered and the solid was washed with methylene chloride. The solvent was removed from the filtrate using a rotary evaporator. The solid obtained was washed with diethyl ether to give high purity of N-chloropyrazinamide ${ }^{16}$. Yield $88 \%$; M.P. $135^{\circ} \mathrm{C}$, Scheme 1.

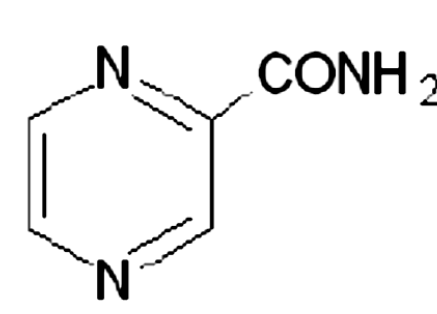

Pyrazinamide (PZA)

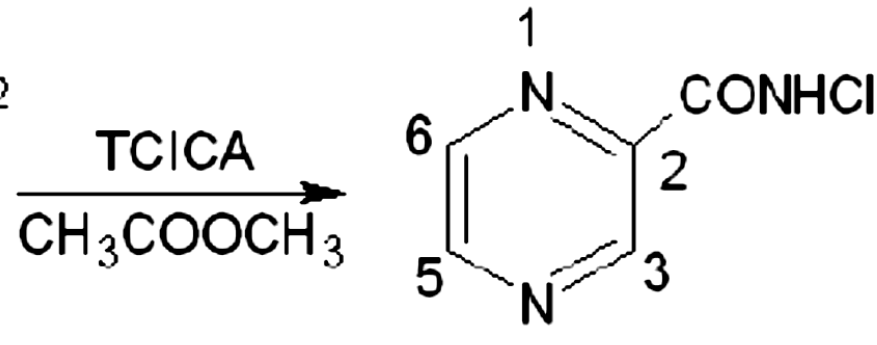

N-chloropyrazinamide (NCPZA)

Scheme 1. Reaction for the preparation N-chloropyrazinamide.

\section{2. Antibacterial activity}

Various concentrations of N-chloropyrazinamide viz., 100, 250 and $500 \mu \mathrm{g}$ are tested for antibacterial activity against Staphylococcus aureus, Escherichia coli, Klebsiella aerogenes and Pseudomonas aeruginosa by disc diffusion technique using Nystatin as a standard antibiotic drug. The nutrient agar prepared by the usual method, was inoculated aseptically with $0.5 \mathrm{ml}$ of overnight subculture of Staphylococcus aureus, Escherichia coli, Klebsiella aerogenes and Pseudomonas aeruginosa in separate conical flasks at $30{ }^{\circ} \mathrm{C}$ and mixed well by gentle shaking. About $25 \mathrm{ml}$ of the contents of the flasks were poured and evenly spread in petridish (90 $\mathrm{mm}$ in diameter) and allowed to set for $2 \mathrm{~h}$. Muller Hinton agar (beef infusion solids $4.0 \mathrm{~g}$, starch $1.5 \mathrm{~g}$, casein hydrolysate $17.5 \mathrm{~g}$, agar $15.0 \mathrm{~g}$, final $\mathrm{pH} 7.4$ \pm 0.2 at $37^{\circ} \mathrm{C}$ ) was used for antimicrobial assay. The assay plates were prepared by spread plate technique with appropriate pathogen inoculums $\left(\sim 10^{4} \mathrm{CFU}\right)$. Using a sterile cork borer, a $7 \mathrm{~mm}$ well was made and filled with $0.05 \mathrm{ml}(50 \mu \mathrm{g} / \mathrm{ml}$ of solution of sample in DMSO). The plates were incubated at $37^{\circ} \mathrm{C}$ for $24 \mathrm{~h}$ and the control was also maintained with $0.05 \mathrm{ml}$ of DMSO in similar manner and the zones of inhibition of the bacterial growth were measured in millimeter. 


\section{3. Antifungal activity}

Aspergillus niger and Mucor were used for testing antifungal activity by disc diffusion method. The culture was maintained on Sabouraud dextrose agar (SDA) slants. SDA medium was inoculated with $72 \mathrm{~h}$ old $0.5 \mathrm{ml}$ suspension of fungal spores in a separate flask. About 25 $\mathrm{ml}$ of the inoculated medium was evenly spread in a sterilized petridish and allowed to set for $2 \mathrm{~h}$. The well $(4 \mathrm{~mm}$ in diameter) were punched in petridish and loaded with $0.05 \mathrm{ml}(10$ $\mu \mathrm{g} / \mathrm{ml}$ ) of solution of sample in DMSO. The plates were incubated at $30{ }^{\circ} \mathrm{C}$ for $4-8 \mathrm{~h}$ after the completion of incubation period, the zones of inhibition of growth in the form of diameter in $\mathrm{mm}$ was measured. Along the test solution in each petridish on well was filled up with solvent which acts as control.

\section{4. In vitro anti-inflammatory activity of NCPZA by hyaluronidase inhibition assay}

The assay was performed according to Ling et $a l^{18}$ and Sigma Protocol. The assay medium consisting of 3 - 5U hyaluronidase (from Sigma - Aldrich, Bangalore) in $100 \mu 120$ $\mathrm{mM}$ sodium phosphate buffer $\mathrm{pH} 7.0$ with $77 \mathrm{mM}$ sodium chloride, $0.01 \%$ BSA was preincubated with different concentrations of the test compound (in dimethyl sulphoxide) for $15 \mathrm{~min}$ at $37^{\circ} \mathrm{C}$. The assay was commenced by adding $100 \mu$ l hyaluronic acid (from Sigma Aldrich, Bangalore; $0.03 \%$ in $300 \mathrm{mM}$ sodium phosphate, $\mathrm{pH} 5.35$ ) to the incubation mixture and incubated for a further $45 \mathrm{~min}$ at $37^{\circ} \mathrm{C}$. The undigested hyaluronic acid was precipitated with $1 \mathrm{ml}$ acid albumin solution made up of $0.1 \%$ bovine serum albumin in $24 \mathrm{mM}$ sodium acetate and $79 \mathrm{mM}$ acetic acid (pH 3.75).

After standing at room temperature for $10 \mathrm{~min}$, the absorbance of the reaction mixture was measured at $600 \mathrm{~nm}$. The absorbance in absence of enzyme was used as the reference value for maximum inhibition. The inhibitory activity of test compound was calculated as the percentage ratio of the absorbance in the presence of test compound versus absorbance in the absence of enzyme. The enzyme activity was checked by control experiment run simultaneously, in which the enzyme was preincubated with $5 \mu \mathrm{l}$ DMSO instead, and followed by the assay procedures described above. Compound was tested in a range of $0.1 \mu \mathrm{g}$ $-1.0 \mu \mathrm{g}$ in the reaction mixture. Indomethacin (Indo) was used as reference standard.

\section{5. In vitro anti-oxidant activity of NCPZA by free radical scavenging activity}

The anti-oxidant activity was evaluated using free radical scavenging activity ${ }^{19}$ by DPPH method. Butylated hydroxyl anisole (BHA) was used as a standard anti-oxidant. Different concentrations $(10 \mu \mathrm{g}, 50 \mu \mathrm{g}$ and $100 \mu \mathrm{g})$ of NCPZA in dimethyl sulphoxide and butylated hydroxy anisole (BHA) were taken in different test tubes. The volume was adjusted to $500 \mu \mathrm{l}$ by adding methanol. Five millilitres of $0.1 \mathrm{mM}$ methanolic solution of 1,1 diphenyl-2-picryl hydrazyl (DPPH) was added to these tubes and shaken vigorously. A control without NCPZA, but with an equivalent amount of methanol was maintained. The tubes were allowed to stand at room temperature for $20 \mathrm{~min}$. The absorbance of the samples was measured at $517 \mathrm{~nm}$. Lower absorbance of the reaction mixture indicates higher free radical scavenging activity. Radical scavenging activity was calculated using the following formula:

$$
\% \text { free radical scavenging activity }=\frac{\text { ODcontrol }- \text { ODsample }}{\text { ODcontrol }} \times 100
$$




\section{6. In vitro anti-hypertensive activity of NCPZA}

NCPZA was tested at three concentrations viz., $1 \mu \mathrm{g}, 5 \mu \mathrm{g}$ and $10 \mu \mathrm{g}$, dissolved in assay buffer (10 mM HEPES buffer containing $0.3 \mathrm{M} \mathrm{NaCl}$ and $10 \mu \mathrm{M}$ zinc sulphate) containing 20 $\mu l$ kidney cortex plasma membranes (ACE enzyme source) and $1 \mathrm{mM}$ Hippuryl-His-Leu as substrate. The compounds were incubated with the enzyme for $10 \mathrm{~min}$ at $37{ }^{\circ} \mathrm{C}$. Then substrate was added and incubated for $45 \mathrm{~min}$ at $37^{\circ} \mathrm{C}$. The reaction was terminated by the addition of $1 \mathrm{M} \mathrm{HCl}$. The yellow colour was developed by the addition of $100 \mu \mathrm{l}$ of pyridine and $50 \mu \mathrm{l}$ of benzene sulphonyl chloride. The yellow colour that formed is measured at 410 $\mathrm{nm}$ in an ELISA Plate Reader (iMARK, BIORAD) ${ }^{20}$. Compounds with an inhibitory potential, block the substrate availability to the enzyme and thereby cause enzyme inhibition leading to no formation of yellow colour. The inhibition is represented in the form of percentage over control. Captopril, a known ACE inhibitor was tested in this assay as a standard compound.

\section{RESULTS AND DISCUSSION}

\section{1. In vitro antibacterial activity of NCPZA}

A) Staphylococcus aureus: Against Staphylococcus aureus, NCPZA has shown to possess a maximum inhibition of $30 \mathrm{~mm}$ diameter at $500 \mu \mathrm{g}$. The minimum inhibition zone exhibited is $18 \mathrm{~mm}$ diameter for $100 \mu \mathrm{g}$. The appreciable inhibition zone noticed is $22 \mathrm{~mm}$ diameter 250 $\mu \mathrm{g}$. The maximum zone of inhibition is exhibited at an optimum concentration of $500 \mu \mathrm{g}$ against the standard inhibition of $35 \mathrm{~mm}$ diameter (Table 1).

B) Escherichia coli: Against Escherichia coli, NCPZA has shown a minimum inhibition zone of $20 \mathrm{~mm}$ diameter at $100 \mu \mathrm{g}$. The appreciable activity has observed at $250 \mu \mathrm{g}$ as $30 \mathrm{~mm}$ diameter zone of inhibition. The other concentration of NCPZA viz., $500 \mu \mathrm{g}$ has shown 42 $\mathrm{mm}$ diameter zone. Hence the optimum level of antibacterial effect of NCPZA for E.coli is $42 \mathrm{~mm}$ against the standard Ciprofloxacin for which the inhibition zone is $38 \mathrm{~mm}$ diameter (Table 1).

C) Klebsiella aerogenes: Against Klebsiella aerogenes, NCPZA has revealed a minimum inhibition zone of $20 \mathrm{~mm}$ diameter at $100 \mu \mathrm{g}$. The appreciable inhibition zone is $18 \mathrm{~mm}$ diameter for $250 \mu \mathrm{g}$ and the maximum inhibition is observed $22 \mathrm{~mm}$ diameter at $500 \mu \mathrm{g}$. Hence the optimum level of antibacterial effect of NCPZA for K.aerogenes is $22 \mathrm{~mm}$ against the standard inhibition of $30 \mathrm{~mm}$ diameter (Table 1).

D) Pseudomonas aeruginosa: Against Pseudomonas aeruginosa, NCPZA has shown a minimum inhibition zone of $15 \mathrm{~mm}$ diameter at $100 \mu \mathrm{g}$ concentration and a maximum inhibition zone of $22 \mathrm{~mm}$ diameter for $500 \mu \mathrm{g}$ concentration. The other concentration of NCPZA viz., $250 \mu \mathrm{g}$ has shown $18 \mathrm{~mm}$ diameter of inhibition (Table 1). 
Table 1. Antibacterial activity of N-chloropyrazinamide.

\begin{tabular}{|c|c|c|c|c|c|c|}
\hline \multirow{2}{*}{ S. No. } & \multirow{2}{*}{ Bacterium } & \multicolumn{5}{|c|}{ Zone of inhibition (mm) } \\
\cline { 3 - 7 } & \multicolumn{2}{|c|}{ Concentration of NCPZA ( $\mathbf{\mu g})$} & $\begin{array}{c}\text { Solvent } \\
\text { control }\end{array}$ & Standard \\
\cline { 3 - 7 } & $\mathbf{1 0 0}$ & $\mathbf{2 5 0}$ & $\mathbf{5 0 0}$ & - & 35 \\
\hline 2. & $\begin{array}{c}\text { Staphylococcus aureus } \\
\text { (NCIM 2079) }\end{array}$ & 18 & 22 & 30 & - & 38 \\
\hline 3. & $\begin{array}{c}\text { Escherichia coli } \\
\text { (NCIM 2065) }\end{array}$ & 20 & 30 & 42 & - & 30 \\
\hline 4. & $\begin{array}{c}\text { Klebsiella aerogenes } \\
\text { (NCIM 2098) }\end{array}$ & 20 & 20 & 28 & - & 35 \\
\hline
\end{tabular}

Standard: Ciprofloxacin $5 \mu \mathrm{g} /$ disc; Solvent: DMSO

\section{2. In vitro antifungal activities of NCPZA}

A) Aspergillus niger: Against Aspergillus niger, NCPZA has shown $18 \mathrm{~mm}$ minimum inhibition of growth at $100 \mu \mathrm{g}$ concentration. The moderate zone of inhibition, $20 \mathrm{~mm}$ has observed at $250 \mu \mathrm{g}$ and the maximum zone of inhibition growth, $35 \mathrm{~mm}$ has found at $500 \mu \mathrm{g}$ which is equivalent to the standard Nystatin fungicide at 100 units/disc. Hence it is found that NCPZA sufficiently inhibits the growth of $A$. niger (Table 2).

B) Mucor: The $50 \%$ zone of inhibition growth is observed at $100 \mu \mathrm{g}$ concentration of NCPZA and $68 \%$ inhibition is shown at $250 \mu \mathrm{g}$. The total inhibition zone at $500 \mu \mathrm{g}$ is $40 \mathrm{~mm}$ which can be compared with the commercial antifungal agent Nystatin $(32 \mathrm{~mm})$ at 100 units/disc (Table 2).

Table 2. Antifungal activity of N-chloropyrazinamide.

\begin{tabular}{|c|c|c|c|c|c|c|}
\hline \multirow{3}{*}{ S. No. } & \multirow{3}{*}{ Fungi } & \multicolumn{5}{|c|}{ Zone of inhibition (mm) } \\
\hline & & \multicolumn{3}{|c|}{ Concentration of NCPZA $(\mu \mathrm{g})$} & \multirow{2}{*}{$\begin{array}{l}\text { Solvent } \\
\text { control }\end{array}$} & \multirow{2}{*}{ Standard } \\
\hline & & 100 & 250 & 500 & & \\
\hline 1. & $\begin{array}{l}\text { Aspergillus Niger } \\
\text { (NCIM 105) }\end{array}$ & 18 & 20 & 35 & - & 35 \\
\hline 2. & $\begin{array}{c}\text { Mucor } \\
\text { (NCIM 108) }\end{array}$ & 16 & 22 & 40 & - & 32 \\
\hline
\end{tabular}

Standard: Nystatin 100 units/disc; Solvent: DMSO.

\section{3. In vitro anti-inflammatory activity of NCPZA}

The hyaluronidase inhibition activity has been carried out to evaluate the antiinflammatory potential of NCPZA. The potency of NCPZA is compared with the standard indomethacin. Different concentrations of NCPZA viz., 10, 50, $100 \mu \mathrm{g}$ shows dose dependent effect of $2.87 \%, 4.81 \%$ and $7.69 \%$ inhibition respectively where as the standard indomethacin at $10 \mu \mathrm{g}$ concentration exhibits $75.93 \%$ inhibition but at $50 \mu \mathrm{g}$ and $100 \mu \mathrm{g}$ 
exhibits much higher activity i.e., beyond the measurable range. Thus, the compound NCPZA exhibits mild to moderate activity compared to the standard indomethacin (Table 3 ).

Table 3. Percentage inhibition of hyaluronidase enzyme by the samples.

\begin{tabular}{|c|c|c|c|}
\hline \multirow{3}{*}{ Sample } & Test concentration $(\boldsymbol{\mu g})$ & O.D at $600 ~ \mathbf{~ m}$ & \% inhibition \\
\cline { 2 - 4 } & $\mathrm{A}_{\mathrm{Max}}$ & 1.080 & 100.00 \\
\hline \multirow{3}{*}{ NCPZA } & 10 & 0.031 & 2.87 \\
\cline { 2 - 4 } & 50 & 0.052 & 4.81 \\
\cline { 2 - 4 } & 100 & 0.079 & 7.69 \\
\hline \multirow{3}{*}{ Indomethacin } & 10 & 0.820 & 75.93 \\
\cline { 2 - 4 } & 50 & 1.256 & $*$ \\
\cline { 2 - 4 } & 100 & 1.340 & $*$ \\
\hline
\end{tabular}

* Beyond measurable range: Much higher activity.

\section{4. In vitro anti-oxidant activity of NCPZA}

NCPZA is evaluated for anti-oxidant activity using in vitro free radical scavenging activity by DPPH method. In this method, various concentrations of NCPZA in dimethyl sulphoxide are used as a test drug whereas butylated hydroxy anisole (BHA) is used as standard anti-oxidant. The extract exhibits a dose dependent free radical scavenging activity.

Anti-oxidants may offer resistance against the oxidative stress by scavenging free radicals, inhibiting lipid peroxidation and thus prevent disease. The anti-oxidant activity of NCPZA at all the concentrations exhibits moderate effect. DPPH is usually used as a reagent to evaluate free radical scavenging activity of anti-oxidant. DPPH is a stable free radical and accepts an electron or hydrogen radical to become a stable diamagnetic molecule. NCPZA is able to reduce the stable free radical to the yellow coloured diphenyl picryl hydrazine.

Table 4. Percentage free radical scavenging activity.

\begin{tabular}{|c|c|c|c|}
\hline Sample & Test concentration $(\boldsymbol{\mu g})$ & O.D at 517 $\mathbf{~ m m}$ & \% activity \\
\hline Control & - & 0.799 & - \\
\hline \multirow{3}{*}{ NCPZA } & 10 & 0.785 & 1.75 \\
\cline { 2 - 4 } & 50 & 0.774 & 3.13 \\
\cline { 2 - 4 } & 100 & 0.745 & 6.76 \\
\hline \multirow{3}{*}{ Indomethacin } & 10 & 0.614 & 23.15 \\
\cline { 2 - 4 } & 50 & 0.412 & 48.44 \\
\cline { 2 - 4 } & 100 & 0.236 & 70.46 \\
\hline
\end{tabular}

The potential decrease in the concentration of DPPH radical due to the scavenging ability of NCPZA at different concentration viz., $10 \mu \mathrm{g}, 50 \mu \mathrm{g}$ and $100 \mu \mathrm{g}$ is found to be 1.75 
$\%, 3.13 \%$ and $6.76 \%$ respectively. With this method, it is possible to determine the antiradical power of an anti-oxidant compound by measuring the decrease in the absorbance of DPPH at $517 \mathrm{~nm}$. A colour change from purple to yellow indicates that the absorbance decreases when the DPPH is scavenged by an anti-oxidant through donation of hydrogen to form stable DPPH molecule. Table 4 illustrates a significant decrease in the concentration of DPPH radical due to the scavenging ability of NCPZA and standard.

\section{5. In vitro anti-hypertensive activity of NCPZA}

NCPZA does not show a significant inhibition of Angiotensin converting enzyme at the tested concentrations. Captopril, a standard ACE inhibitor, displays $50 \%$ inhibition at its IC50 concentration (Table 5).

Table 5. Inhibitory profile of NCPZA.

\begin{tabular}{|c|c|}
\hline NCPZA & \% inhibition \\
\hline $10 \mu \mathrm{g}$ & 6.3 \\
\hline $5 \mu \mathrm{g}$ & 2.5 \\
\hline $1 \mu \mathrm{g}$ & 8.0 \\
\hline Captopril $(15 \mathrm{~nm})$ & 55.0 \\
\hline
\end{tabular}

\section{CONCLUSION}

The antibacterial activity of NCPZA reveals that different levels of inhibition of growth as well as different levels of optimum concentration of the compound for the chosen bacterial species. E. coli has shown the maximum level of inhibition of growth of $42 \mathrm{~mm}$ at optimum concentration at $500 \mu \mathrm{g}$. Staphylococcus aureus and Klebsiella aerogenes have exhibited the maximum level of inhibition of growth $30 \mathrm{~mm}$ and $28 \mathrm{~mm}$ at optimum concentration of 500 $\mu \mathrm{g}$. Pseudomonas aeruginosa has shown the maximum level of inhibition of growth $22 \mathrm{~mm}$ at an optimum concentration of $500 \mu \mathrm{g}$. Thus, NCPZA as antibacterial agent is comparable with commercial antibiotic drug, Ciprofloxacin.

The antifungal activity of NCPZA against the chosen fungi namely Aspergillus niger and Mucor showed a very good inhibition of growth at optimum concentration. Mucor has found to possess $40 \mathrm{~mm}$ zone of inhibition at $500 \mu \mathrm{g}$ concentration against the standard Nystatin and Aspergillus niger has shown $35 \mathrm{~mm}$ growth of inhibition against the standard. Thus, NCPZA an antifungal agent is comparable with commercial antifungal agent Nystatin.

The anti-inflammatory activity of NCPZA against the standard indomethacin exhibits mild to moderate activity. There is a significant decrease in the concentration of DPPH radical due to the scavenging ability of NCPZA and standard. NCPZA is screened for antihypertensive activity against the standard captopriol. There is no significant inhibition of Angiotensin converting enzyme at different concentrations. 


\section{References}

[1] Michael H. Cynamon, Sally P. Klemens, Tso Sheng Chou, Rayomand H. Gimi, John T. Welch, Journal of Medicinal Chemistry 35 (1992) 1212-1215.

[2] Setsuko Yamamoto, Ichiro Toida, Nanao Watanabe, Toshikazu Ura, Antimicrobial Agents and Chemotherapy 39(9) (1995) 2088-2091.

[3] Veronika Opletalova, Jiri Hartl, Asmita Patel, Karel Palat Jr, Vladimir Buchta, Farmaco 57 (2002) 135-144.

[4] Martin Dolezal, Lenka Tumova, Diana Kesetovicova, Jiri Tuma, Katarina Kraloya, Molecules 12(12) (2007) 2589-2598.

[5] Martin Dolezal, Lukas Palek, Jarmila Vinsova, Vladimir Buchta, Josef Jampilek, Katarina Kraloya, Molecules 11(4) (2006) 242-256.

[6] A. W. Cuthbert, J. M. Edwardson, Journal of Pharmacy and Pharmacology 31(6) (1979) 382-386.

[7] B. A. Ellsworth, et. al., Bioorganic Medicinal Chemistry Letters 17(14) (2007) 3978-3982.

[8] Martin Dolezal, Jan Zitko, Diana Kesetovicova, Jiri Kunes, Michaela Svobodova, Molecules 14(10) (2009) 4180-4189.

[9] Lenka Tumova, Jiri Tuma, Klara Megusar, Marin Dolezal, Molecules 15(1) (2010) 331-340.

[10] M. Dolezal, J. Zitko, Z. Osicka, J. Kunes, M. Vejsova, V. Buchta, J. Dohnal, J. Jampilek, K. Kralova, Molecules 15(12) (2010) 8567-8581.

[11] Lenka Tumova, Jiri Tuma, Martin Dolezal, Molecules 16(11) (2011) 9142-9152.

[12] S. Suzuki, A. Inoue, Chemical Abstracts 113 (1990) $218276 \mathrm{t}$.

[13] T. Sado, A. Inoue, Chemical Abstracts 113 (1990) 78422k.

[14] Talaat Ibrahim El-Emary, Journal of Chinese Chemical Society 53(2) (2006) 391-401.

[15] H. S. El-Kashef, T. I. El-Emary, M. Gasquet, P. Timon-David, J. Maldonado, P. Vanelle, Pharmazie 55(8) (2000) 572-576.

[16] S. Parimala Vaijayanthi, N. Mathiyalagan, International Journal of Research in Organic Chemistry 2(3) (2012) 13-15.

[17] S. K. Ling, T. Tanaka, I. Kouno, Biological \& Pharmaceutical Bulletin 26(3) (2003) 352-356.

[18] S. Kumar, D. Kumar, Manjusha, K. Saroha, N. Singh, B. Vashishta, Acta Pharmaceutica 58 (2008) 215-220.

[19] V. K. Jimsheena, Analytical Chemistry 81 (2009) 9388-9394.

[20] Nigel M. Hooper, Anthony J. Turner, Biochemical Journal 241 (1987) 625-633. 